\title{
Race Determination and Vegetative Compatibility Grouping of Fusarium oxysporum f. sp. melonis from South Africa
}

\author{
W. Schreuder, Hygrotech Seed, P.O. Box 379, Strand 7140, South Africa; S. C. Lamprecht, ARC, Plant Protection \\ Research Institute, Private Bag X5017, Stellenbosch 7599, South Africa; and G. Holz, Department of Plant Pathol- \\ ogy, University of Stellenbosch, Private Bag X1, Matieland 7602, South Africa
}

\begin{abstract}
Schreuder, W., Lamprecht, S. C., and Holz, G. 2000. Race determination and vegetative compatibility grouping of Fusarium oxysporum f. sp. melonis from South Africa. Plant Dis. 84:231234.

Isolates of Fusarium oxysporum f. sp. melonis (72 total) obtained from 30 fields in 17 melonproducing regions in South Africa were race typed, using differential cvs. CM 17187, Doublon, Perlita, and Topmark, and grouped on the basis of vegetative compatibility. Fifty-four isolates were identified as race 0 , eight as race 1 , and ten as race 2 . Race 0 occurred in 15 of 17 regions, whereas race 1 was sporadically recovered. Race 2 was obtained from only four fields located in one geographic region. Perlita plants (carrying the gene Fom3) inoculated with local isolates of races 0 and 2 and reference isolates of race 0 became stunted, and their leaves became yellow, thickened, and brittle. Using two inoculation methods, similar symptoms were induced by reference and local isolates of race 0 on Perlita seedlings. The results indicated that Fom3 in Perlita confers a tolerant reaction compared with the resistant reaction of gene Foml in Doublon and, therefore, should not be used alone in race determination tests. All isolates belonged to vegetative compatibility group 0134 , indicating a high degree of genetic homogeneity among the South African F. oxysporum f. sp. melonis population.
\end{abstract}

Fusarium wilt, caused by Fusarium oxysporum Schlechtend. emend. W.C. Snyder \& H.N. Hans. f. sp. melonis Leach \& Currence, is an economically important disease of melon (Cucumis melo L.) in South Africa and other areas of the world $(11,20)$. Because of the persistence of the pathogen in soil, the disease is best managed using wilt-resistant melon cultivars. Risser et al. (19) divided four races of $F$. oxysporum $\mathrm{f}$. sp. melonis based on three differential cultivars: race 0 attacks only cultivars that lack any genes for resistance to $F$. oxysporum f. sp. melonis (e.g., Charentais T); race 1 overcomes the resistance gene Fom 1 in cv. Doublon; race 2 overcomes the resistance gene Fom 2 in cv. CM 17187; and race 1,2 overcomes both resistance genes. Race 1,2 is divided into race 1,2 wilt and yellow strains. Inheritance studies conducted by Zink and Gubler (22) revealed that, similar to Doublon (Fom1), resistance in cv. Perlita is conferred toward races 0 and 2 by another dominant gene, Fom3.

Isolates of $F$. oxysporum f. sp. melonis from various geographic regions have been grouped on the basis of vegetative compatibility $(8,9,12)$. This approach, initiated

Corresponding author: W. Schreuder
E-mail: wouter@hygrotech.co.za

Accepted for publication 20 November 1999.

Publication no. D-2000-0118-01R

(C) 2000 The American Phytopathological Society by Puhalla (18), provides a means of distinguishing subspecific groups in $F$. oxysporum based on the genetics of the fungus rather than on the host-pathogen interaction. In F. oxysporum f. sp. melonis, eight vegetative compatibility groups (VCGs) have been characterized worldwide $(8,9,12)$. The relationship between race and VCG, however, is complex $(6,11)$. Isolates of all four races of $F$. oxysporum f. sp. melonis have each been found in more than one VCG, indicating that no race represents a genetically homogeneous group of isolates, and in contrast, all four races can be present in a single VCG. VCG diversity within and between geographic regions also has been found, although some VCGs are predominantly from specific geographic regions (9), with VCG 0138 restricted to Israel (12). Although the race-VCG relationship cannot be used to identify races, it is useful in characterizing genetic diversity within the pathogen population. The correlation between mtDNA and VCG in $F$. oxysporum f. sp. melonis helped confirm the importance of VCG as an indicator of genetically isolated populations (10). Jacobson and Gordon (11), therefore, suggested that F. oxysporum f. sp. melonis isolates should be described by both virulence and VCG, because together they reveal more information than either characteristic alone.

Although Fusarium wilt occurs annually in fields in the melon-producing regions of South Africa, little is known about its origin or the distribution of races. No race determination tests have been conducted with South African F. oxysporum f. sp. melonis isolates, and meaningful recommendations for choice of resistant cultivars cannot be made. Prior to 1989 , most commercial cultivars lacked resistance to $\mathrm{Fu}-$ sarium wilt, and those that had resistance were cultivated primarily for their fruit characteristics. The purpose of our study was to characterize the race and vegetative compatibility of $F$. oxysporum f. sp. melonis isolates collected in the major melon-producing areas of South Africa, their geographic distribution, and their possible relatedness to isolates of $F$. oxysporum $\mathrm{f}$. sp. melonis from other countries. Although isolates of this pathogen are given the classification forma specialis melonis because of their host specificity toward C. melo, crosspathogenicity of this and other formae speciales among the Cucurbitaceae has been reported (2,7). Consequently, pathogenicity tests on other Cucurbitaceae were conducted.

\section{MATERIALS AND METHODS}

Selected isolates. During 1989 to 1995 , melon plants with typical Fusarium wilt symptoms $(15,20)$ were collected from 30 melon fields in the major melon-producing regions of South Africa and transported to a laboratory. Diseased stems and roots were washed under a fine spray of tap water, surface-disinfested $(1 \mathrm{~min}$ in $0.5 \% \mathrm{NaOCl}$, rinsed in distilled water, followed by $1 \mathrm{~min}$ in $70 \%$ ethanol), and air-dried on a laminar flow bench. Stems and roots were split in half, and the parts were aseptically dissected and plated on Komada's (13) medium amended with Tergitol NP-10 at $1 \mathrm{ml} / \mathrm{liter}$ (17). Plates were incubated at 17 to $23^{\circ} \mathrm{C}$ for 8 to 14 days on a laboratory bench. Colonies exhibiting the characteristic morphology of $F$. oxysporum (13) were transferred to divided petri dishes containing potato dextrose agar with $0.02 \%$ novostreptomycin $\left(\mathrm{PDA}^{+}\right)$and carnation leaf agar (5) with $0.02 \%$ novostreptomycin. Divided plates were incubated at $20^{\circ} \mathrm{C}$ for 14 to 21 days under intermittent light (12 h of fluorescent plus black-light cycles), and single-conidial isolates were made on water agar as described by Nelson et al. (16). Singleconidial isolates were identified according to Nelson et al. (16), and representative isolates were lyophilized. Isolates (72 total: 1 to 4 per melon field) obtained from 17 regions were selected for VCG and race determination. Isolates were deposited in the National Collection of Fungi (PREM 51304 
to 51353), Pretoria, South Africa. F. oxyATCC 28857, ATCC 28858, ATCC 28861, ATCC 28826, ATCC 32669, Fom 8803, I1, T61, R12w, and 466C (Table 1) were used as references in race determination.

Race determination. Virulence was determined by the pipette inoculation method of Latin and Snell (14). Lyophilized cultures were grown on $\mathrm{PDA}^{+}$. After 5 days, mycelial plugs ( $3 \mathrm{~mm}$ diameter) were taken from the actively growing colony margins of each isolate, transferred to $100 \mathrm{ml}$ of a potato dextrose broth (10 g/liter; Difco Laboratories, Detroit), and incubated at $25^{\circ} \mathrm{C}$ for 5 days in a rotary incubator $(150 \mathrm{rpm})$. The contents of each flask was filtered through four layers of sterile cheesecloth, and the density of the predominantly microconidial suspension of each isolate was determined with a hemacytometer and adjusted to $10^{6}$ conidia per ml. Seeds of four differential melon cultivars, CM 17187 (Fom 2$)$, Doublon (Fom 1), Perlita (Fom 3), and Topmark (no resistance genes) (8), were surface-disinfested with a 5\% calcium hypochlorite solution for $5 \mathrm{~min}$, rinsed twice in sterile distilled water, and planted in cell-type plastic growing trays (1 seedling per $60-\mathrm{ml}$ cell) filled with a pasteurized commercial potting mixture (peat/vermiculite/polystyrene, 18:12:1, mass/mass], $\mathrm{pH}$ 5.8 [Hygrotech Seed, Strand, South Africa]). Each growing tray contained 128 removable cells. Seeds were obtained from J. P. Crill (Colorado), T. R. Gordon (University of California), Hollar Seeds (Colorado), and Petoseed (California). Trays were incubated in a growth chamber at 18 and $25^{\circ} \mathrm{C}$, night and day, temperatures under cool white fluorescent light, with a 14-h photoperiod. Seedlings were inoculated 11 to 12 days (expansion of first true leaf stage) after planting. The inoculum suspension $(5 \mathrm{ml})$ was delivered to the substrate around each seedling. Control plants received sterile diluted potato dextrose broth. At least five seedlings of each cultivar were inoculated, and each isolate was tested at least twice. After inoculation, seedlings were watered once a week with a soluble fertilizer at $2 \mathrm{~g} /$ liter (Chemicult Hydrosporum f. sp. melonis isolates ATCC 28856 ,

ponic Nutrient). Disease development, as described by Jacobson and Gordon (8) (stunting, chlorosis, necrosis, and death), was recorded weekly, and final assessments were made after 28 days. Isolates were considered virulent on a cultivar when at least $80 \%$ of the seedlings developed symptoms and were considered avirulent when no symptoms were evident. Isolates were assigned to the appropriate race based on their virulence on differential cultivars.

Cross-pathogenicity. $F$. oxysporum f. sp. melonis isolates (30 total) obtained from different local melon fields were selected randomly and tested for pathogenicity on cucumber (Cucumis sativus L. 'Marketer') and watermelon (Citrullus lanatus (Thunb.) Matsum. \& Nakai 'Sugar Baby'). Cucumber and watermelon seedlings were grown, inoculated, and rated for disease development as described earlier.

Vegetative compatibility. VCGs were determined using complementation of nitrate nonutilizing (nit) mutants as a visual indicator of heterokaryon formation (18). Nit mutants were generated from each of the 72 F. oxysporum f. sp. melonis isolates on potato sucrose agar containing $1.5 \% \mathrm{KClO}_{3}$ (4). The concentration of $\mathrm{KClO}_{3}$ was increased to $3 \%$ for isolates that were not restricted by $1.5 \% \mathrm{KClO}_{3}$ (8). The fastgrowing, chlorate-resistant sectors originating from the initially restricted colony, which grew thinly but expansively on Puhalla's minimal medium (MM) (18), were considered nit mutants. Nit mutants were phenotypically classified by their growth on basal medium (MM without $\mathrm{NaNO}_{3}$ ) amended with one of several nitrogen sources (3). Nit mutants (nit1, nit3, and NitM) generated from each of the $F$. oxysporum $\mathrm{f}$. sp. melonis isolates were paired with tester strains (nit1 and NitM) of each of the established VCGs obtained from T. R. Gordon (P2/6, P2/1, Pt2/1, Pt3/1, T61/1, R12w/13, R12w/14, 660A/1, 660A/17, I1/1, I1/5, $\mathrm{K} 419 / 2$, K419/5, A3/6, and A3/4) or generated from wild-type isolates known to belong to a specific VCG. Pairings were made on MM in 9-cm petri dishes incubated at room temperature $\left(18\right.$ to $\left.23^{\circ} \mathrm{C}\right)$ in the dark and scored for complementation 7

Table 1. Reference isolates of Fusarium oxysporum f. sp. melonis representing four physiologic races

\begin{tabular}{llll}
\hline Strain & Race $^{\mathbf{a}}$ & \multicolumn{1}{c}{ Origin } & Source $^{\mathbf{b}}$ \\
\hline ATCC 28856 & 0 & France & A \\
ATCC 28857 & 1 & France & A \\
ATCC 28858 & 1,2 & France & A \\
ATCC 28861 & 2 & Japan & A \\
ATCC 28862 & 1 & Israel & A \\
ATCC 32669 & 2 & Michigan, U.S. & A \\
Fom 8803 & 0 & Spain & B \\
I1 & 0 & Israel & C \\
T61 & 2 & Unknown & C \\
R12w & 1,2 & France & D \\
466C & 0 & Maryland, U.S. &
\end{tabular}

a Race designation according to Risser et al. (19).

${ }^{\text {b }} \mathrm{A}=$ American Type Culture Collection, Manassas, VA; B = R. M. Jiménez Díaz, Universidad de Cordoba, Cordoba, Spain; C = T. R. Gordon, University of California, Davis; D = D. M. S. Spinks, Hollar Seeds, Rocky Ford, CO. and 14 days later. When a mutant successfully formed a complementary heterokaryon with a given tester, its parent was placed in the corresponding VCG.

\section{RESULTS}

Race determination. The reference isolates caused the expected disease reactions on differential cvs. CM 17187, Doublon, and Topmark. All were highly virulent on susceptible cv. Topmark. The race 1 isolates were avirulent on CM 17187 (Fom2) but highly virulent on both Doublon (Foml) and Perlita (Fom3). The race 2 isolates were highly virulent on CM 17187 (Fom2) but avirulent on Doublon (Foml) and Perlita (Fom3). The race 0 reference isolates were avirulent on both Doublon (Foml) and CM 17187 (Fom2). However, all four race 0 reference isolates induced stunting in Perlita (Fom3) plants. Leaves of stunted Perlita seedlings became yellow, thickened, and brittle. The virulence test was repeated four times, using Perlita (Fom3) seed lots obtained from the sources mentioned earlier and a range of inoculum concentrations $\left(1 \times 10^{5}, 5 \times 10^{5}, 1 \times 10^{6}\right.$, and $5 \times 10^{6}$ conidia per $\mathrm{ml}$ ). To further verify the finding, reference isolate ATCC 28856 (race 0) and one of the race 0 isolates from South Africa (PREM 51308) were used to inoculate Perlita seedlings (30 seedlings per treatment, including water-treated controls) by the root-dip method (22). In all experiments, race 0 isolates indiscriminately caused stunting of Perlita, with leaves becoming yellow, thickened, and brittle.

Virulence of $F$. oxysporum f. sp. melonis isolates and their geographic and host origins are given in Table 2. All isolates were highly virulent on susceptible cv. Topmark. A total of 54 isolates obtained from 15 of the 17 regions surveyed were avirulent on CM 17187 (Fom2) and Doublon (Fom1) and, therefore, assigned to race 0 . Of the race 0 isolates, 45 were recovered from cultivars with no resistance to $F$. oxyspor$u m$ f. sp. melonis, 5 were recovered from cvs. Doral (fields 16 and 17) and Saticoy (field 6), in which resistance to races 0 and 2 is conferred by Fom3 (A. Comrie, personal communication), and 4 were recovered from cultivars resistant to races 0 and 1 . Three of the latter isolates originated from cv. Helios (Fom2) plants (field 30) infested with root-knot nematodes, which could have contributed to the stunting and yellowing symptoms or reduced plant resistance to $F$. oxysporum f. sp. melonis (1). Another isolate was recovered from a Galia 5 (Fom2) plant (field 27) from which a race 2 isolate also was recovered. The race 0 isolates, however, all induced similar symptoms on Perlita (Fom3) seedlings, as was found with the reference race 0 isolates.

Eight isolates avirulent on CM 17187 (Fom2) but highly virulent on both Doublon (Fom 1) and Perlita (Fom3) were assigned to race 1 . These isolates originated from five regions, in three of which races 
0 and 1 were recovered from the same fields.

The 10 remaining isolates were highly virulent on CM 17187 (Fom2) but avirulent on Doublon (Foml) and, therefore, assigned to race 2 . These isolates, however, caused the same stunting and yellowing symptoms on Perlita (Fom3) as was found previously with race 0 isolates. The isolates were all recovered from Galia 5 (Fom2), Helios (Fom2), and Limor (Fom2) plants, which are all resistant to $F$. oxysporum $\mathrm{f}$. sp. melonis races 0 and 1 , sampled from four separate fields (fields 11, 12, 27, and 30) in three regions located in one geographic area. All four of the fields had a history of Fusarium wilt, from which $F$. oxysporum f. sp. melonis race 0 was previously identified. After planting race 0 - and 1-resistant cultivars during two successive years in these fields, race 2 isolates were recovered after plants began to wilt during the second year of planting (Table 2).

Cross-pathogenicity. The $30 \quad F$. oxysporum f. sp. melonis isolates did not induce any Fusarium wilt symptoms on cucumber and watermelon seedlings.

Vegetative compatibility. The South African $F$. oxysporum f. sp. melonis isolates readily produced chlorate-resistant sectors. At least three nit mutants (nit1, nit3, and NitM) were generated from each of the South African isolates and paired with the testers from each of the established VCGs. All 72 South African isolates, which represent 3 distinct virulent phenotypes, formed complementary heterokaryons with the VCG 0134 testers.

\section{DISCUSSION}

This study demonstrated a high degree of VCG homogeneity among South African isolates of $F$. oxysporum f. sp. melonis. The 72 F. oxysporum f. sp. melonis isolates, comprising 3 races recovered between 1989 and 1995 from diseased melon plants sampled from 17 melon-producing regions, all belonged to VCG 0134 . This VCG is considered to be predominantly European (11), suggesting that the South African wilt-inducing $F$. oxysporum f. sp. melonis population was introduced from Europe. The lack of cross-pathogenicity to cucumber and watermelon corroborated the host specificity toward Cucumis melo of the local isolates and validated the forma specialis concept in cucurbits (21).

The data, furthermore, indicated that the race 2 isolates probably were not introduced to South Africa independently but were derived locally from race 0 isolates. This hypothesis is substantiated by the occurrence of race 2 in melon fields in the production regions of Paarl (fields 11 and 12), Wellington (field 27), and Worcester (field 30 ). Prior to 1989 , most cultivars commercially cultivated in fields in these regions lacked resistance to Fusarium wilt. In 1990 (fields 11, 12, and 27) and 1992 (field 30), only race 0 was recovered from diseased melon plants from these four fields. Cultivars resistant to races 0 and 1 (Fom2) were introduced during the following years and planted repeatedly in the same fields. Two years after introducing these cultivars producers reported serious yield losses, and race 2 was obtained from these fields. Bouhot (2) also found that after introducing new resistant melon cultivars into France they were attacked by $F$. oxysporum f. sp. melonis by the second year of planting. He showed that through use of chemical treatments to induce mutations in $F$. oxysporum f. sp. melonis isolates, one race could mutate into another, and the pathogenicity factors in the forms could coexist in one isolate.

Considering this observation and the VCG data, it seems likely that race 2 was derived from the isolates of race 0 that previously predominated in these fields. The fact that in South Africa race 2 was found only in race 0 -infested fields cultivated with resistant cultivars (Fom2), that the South African race 2 isolates differed from the race 2 reference isolates in their ability to attack Perlita (Fom3), and that both South African phenotypes (races 0 and 2) belonged to the same VCG make it unlikely that race 2 was introduced into these four fields from a foreign source. The host genotype seems to have played a definite role in the establishment and buildup of the local race 2 population. This conclusion does not conform to the findings of Bouhot (2) that race 1,2 existed in France at least 12 years before melon cultivars were bred for resistance to the race.

The susceptible reaction of Perlita (Fom3) to the South African race 0 and 2 isolates, as well as to the reference race 0 isolates, cast doubt on the resistance characteristics of this cultivar. According to Jacobson and Gordon (8) plants are considered diseased if they are stunted and chlorotic. These symptoms were consistently caused on Perlita (Fom3) seedlings inoculated with the South African race 0 and 2 isolates and reference race 0 isolates. A similar reaction was obtained when a different inoculation method (root dip) was used. Based on these criteria, our results demonstrated that when Perlita (Fom3) alone is used as a differential to determine $F$. oxysporum f. sp. melonis races, incorrect interpretations can be made. It seems that the Fom 3 gene in

Table 2. Race determination for 72 isolates of Fusarium oxysporum f. sp. melonis recovered from diseased plants in 30 fields in 17 melon-producing regions in South Africa

\begin{tabular}{|c|c|c|c|c|c|c|}
\hline Region & Field & $\begin{array}{c}\text { Sampling } \\
\text { date }\end{array}$ & $\begin{array}{c}\text { Cultivar of } \\
\text { origin }^{\mathrm{a}}\end{array}$ & $\begin{array}{c}\text { Resistance } \\
\text { gene }^{\mathbf{b}}\end{array}$ & $\begin{array}{c}\text { Races } \\
\text { recovered }^{\mathbf{c}}\end{array}$ & $\begin{array}{c}\text { No. of } \\
\text { isolates }\end{array}$ \\
\hline Citrusdal & 1 & Feb. 1991 & Galia & $\ldots$ & 0 & 1 \\
\hline \multirow[t]{3}{*}{ Clanwilliam } & 2 & Oct. 1990 & Galia & $\ldots$ & 0 & 4 \\
\hline & 3 & Nov. 1990 & Lyon Jumbo & $\ldots$ & 0,1 & 3 \\
\hline & 4 & Nov. 1990 & Lyon Jumbo & $\ldots$ & 0 & 1 \\
\hline De Doorns & 5 & Nov. 1989 & Gold King & $\ldots$ & 0 & 4 \\
\hline Douglas & 6 & Nov. 1992 & Saticoy & Fom3 & 0 & 1 \\
\hline \multirow[t]{2}{*}{ Kimberley } & 7 & Feb. 1992 & Saticoy & Fom3 & 1 & 2 \\
\hline & 8 & Feb. 1992 & Sutter & $\ldots$ & 1 & 1 \\
\hline Klapmuts & 9 & Jan. 1991 & Early Dawn & Fom1 & 1 & 1 \\
\hline Mooreesburg & 10 & Nov. 1990 & Galia & $\ldots$ & 0 & 2 \\
\hline \multirow[t]{4}{*}{ Paarl } & 11 & Sep. 1990 & Galia & $\ldots$ & 0 & 2 \\
\hline & 11 & Nov. 1992 & Galia 5 & Fom2 & 2 & 2 \\
\hline & 12 & Nov. 1990 & Ogen & $\ldots$ & 0 & 2 \\
\hline & 12 & Jan. 1993 & Galia 5, Limor & Fom2 & 2 & 3 \\
\hline Philipi & 13 & Feb. 1991 & HSR 444 & $\ldots$ & 0 & 1 \\
\hline Piketberg & 14 & Nov. 1990 & Lyon Jumbo & $\ldots$ & 0 & 3 \\
\hline \multirow{3}{*}{ Porterville } & 15 & Nov. 1990 & Yellow Canaria & $\ldots$ & 0 & 1 \\
\hline & 16 & Nov. 1991 & Doral & Fom3 & 0 & 2 \\
\hline & 17 & Mar. 1995 & Doral & Fom3 & 0 & 2 \\
\hline \multirow[t]{3}{*}{ Robertson } & 18 & Oct. 1991 & Yellow Canaria & $\ldots$ & 0 & 1 \\
\hline & 19 & May 1992 & Yellow Canaria & $\ldots$ & 0 & 1 \\
\hline & 20 & May 1992 & Yellow Canaria & $\ldots$ & 0 & 1 \\
\hline Stanford & 21 & Mar. 1993 & Galera & $\ldots$ & 0 & 2 \\
\hline Vioolsdrift & 22 & Jan. 1992 & Imperial 45 & $\ldots$ & 0 & 2 \\
\hline \multirow[t]{2}{*}{ Vredendal } & 23 & Nov. 1991 & Galia & $\ldots$ & 0 & 2 \\
\hline & 24 & Nov. 1991 & Galia & $\ldots$ & 0 & 1 \\
\hline \multirow[t]{4}{*}{ Wellington } & 25 & Nov. 1990 & Early Sweet & $\ldots$ & 0,1 & 3 \\
\hline & 26 & Dec. 1990 & Early Sweet & $\ldots$ & 0 & 2 \\
\hline & 27 & Dec. 1990 & Lyon Jumbo & $\ldots$ & 0 & 2 \\
\hline & 27 & Nov. 1993 & Galia 5 & Fom2 & 0,2 & 4 \\
\hline \multirow[t]{5}{*}{ Worcester } & 28 & Nov. 1989 & Yellow Canaria & $\ldots$ & 0,1 & 5 \\
\hline & 29 & Nov. 1990 & Yellow Canaria & $\ldots$ & 0 & 3 \\
\hline & 30 & Nov. 1992 & Helios & Fom2 & 0 & 2 \\
\hline & 30 & Jan. 1993 & Helios & Fom2 & 0 & 1 \\
\hline & 30 & Feb. 1995 & Helios & Fom2 & 2 & 2 \\
\hline
\end{tabular}

${ }^{a}$ Melon cultivars from which $F$. oxysporum f. sp. melonis isolates were recovered.

${ }^{\mathrm{b}}$ Resistance genotypes of melon cultivars according to South African seed company listings (A Comrie, personal communication $) ; \ldots=$ no resistance.

${ }^{\mathrm{c}}$ Race designation according to differential cvs. CM 17187 (Fom2), Doublon (Fom1), Perlita (Fom3) and Topmark (no resistance genes). 
Perlita conferred a tolerant reaction toward race 0 and the South African race 2 isolates, not a resistant reaction similar to the gene Fom 1 in Doublon. Zink and Gubler (22) also indicated that Perlita (Fom3) did not show wilt symptoms when inoculated (root-dip method) with a conidial suspension containing races 0 and 2 at less than $5 \times 10^{5}$ conidia per ml. However, in our experiments using the pipette inoculation method, isolates of race 0 were able to induce stunting at an inoculum concentration of $1 \times 10^{5}$ conidia per ml. Furthermore, in commercial fields, race 0 was able to induce typical Fusarium wilt symptoms and cause severe yield losses on cultivars possessing the Fom 3 gene (fields 6, 16, and 17). Therefore, Fom 3 does provide not reliable results in race determination tests, and also is unreliable as a control measure in the field against races 0 and 2 . The disease reaction of Perlita (Fom3) toward races 0 and 2 is currently being investigated.

\section{ACKNOWLEDGMENTS}

We thank T. R. Gordon, R. M. Jiménez Díaz, and D. M. S. Spinks for supplying fungal isolates; J. P. Crill, Petoseed, T. R. Gordon, and Hollar Seeds, for providing seed; A. C. van den Heever and A. S. Venter for invaluable technical assistance; and L. Schreuder for typing the manuscript.

\section{LITERATURE CITED}

1. Bergeson, G. B. 1975. The effect of Meloidogyne incognita on the resistance of four muskmelon varieties to Fusarium wilt. Plant Dis. Rep. 59:410-413.

2. Bouhot, D. 1981. Some aspects of the patho- genic potential in formae speciales and races of Fusarium oxysporum on Cucurbitaceae. Pages 318-326 in: Fusarium: Diseases, Biology, and Taxonomy. P. E. Nelson, T. A. Toussoun, and R. J. Cook, eds. Pennsylvania State University Press, University Park.

3. Correll, J. C., Klittich, C. J. R., and Leslie, J. F. 1987. Nitrate nonutilizing mutants of $F u$ sarium oxysporum and their use in vegetative compatibility tests. Phytopathology 77:16401646.

4. Correll, J. C., Puhalla, J. E., and Schneider, R. W. 1986. Identification of Fusarium oxysporum f. sp. apii on the basis of colony size, virulence, and vegetative compatibility. Phytopathology 76:396-400.

5. Fisher, N. L., Burgess, L. W., Toussoun, T. A., and Nelson, P. E. 1982. Carnation leaves as a substrate and for preserving cultures of $\mathrm{Fu}$ sarium species. Phytopathology 72:151-153.

6. Gennari, S., and D'Ercole, N. 1994. Determination of vegetative compatibility groups in Fusarium oxysporum f. sp. melonis isolates. Phytopathol. Mediter. 33:63-70.

7. Gerlagh, M., and Blok, W. J. 1988. Fusarium oxysporum f. sp. cucurbitacearum n.f. embracing all formae speciales of $F$. oxysporum attacking cucurbitaceous crops. Neth. J. Plant. Pathol. 94:17-31.

8. Jacobson, D. J., and Gordon, T. R. 1988. Vegetative compatibility and self-incompatibility within Fusarium oxysporum f. sp. melonis. Phytopathology 78:668-672.

9. Jacobson, D. J., and Gordon, T. R. 1990. Further investigations of vegetative compatibility within Fusarium oxysporum f. sp. melonis. Can. J. Bot. 68:1245-1248.

10. Jacobson, D. J., and Gordon, T. R. 1990. Variability of mitochondrial DNA as an indicator of relationships between populations of $\mathrm{Fu}$ sarium oxysporum f. sp. melonis. Mycol. Res. 94:734-744.

11. Jacobson, D. J., and Gordon, T. R. 1991. Fusarium oxysporum f. sp. melonis: A case study of diversity within a forma specialis. Phytopathology 81:1064-1067.

12. Katan, T., Katan, J., Gordon, T. R., and Pozniak, D. 1994. Physiologic races and vegetative compatibility groups of Fusarium oxysporum $\mathrm{f}$. sp melonis in Israel. Phytopathology 84:153-157.

13. Komada, H. 1975. Development of a selective medium for quantitative isolation of Fusarium oxysporum from natural soil. Rev. Plant Prot. Res. 8:114-124.

14. Latin, R. X., and Snell, S. J. 1986. Comparison of methods for inoculation of muskmelon with Fusarium oxysporum f. sp. melonis. Plant Dis. 70:297-300.

15. Mas, P., Molot, P. M., and Risser, G. 1981. Fusarium wilt of muskmelon. Pages 169-177 in Fusarium: Diseases, Biology, and Taxonomy. P. E. Nelson, T. A. Toussoun, and R. J. Cook, eds. Pennsylvania State University Press, University Park.

16. Nelson, P. E., Toussoun, T. A., and Marasas, W. F. O. 1983. Fusarium species: An Illustrated Manual for Identification. Pennsylvania State University Press. University Park.

17. Puhalla, J. E. 1984. A visual indicator of heterokaryosis in Fusarium oxysporum from celery. Can J. Bot. 62:540-545.

18. Puhalla, J. E. 1985. Classification of strains of Fusarium oxysporum on the basis of vegetative compatibility. Can J. Bot. 63:179-183.

19. Risser, G., Banihashemi, Z, and Davis, D. W 1976. A proposed nomenclature of Fusarium oxysporum f. sp. melonis races and resistance genes in Cucumis melo. Phytopathology 66: 1105-1106.

20. Sherf, A. F., and Macnab, A. A. 1986. Vegetable Diseases and their Control. John Wiley \& Sons, New York

21. Snyder, W. C., and Hansen, H. N. 1940. The species concept in Fusarium. Am. J. Bot. 27: 64-67.

22. Zink, F. W., and Gubler, W. D. 1985. Inheritance of resistance in muskmelon to Fusarium wilt. J. Am. Soc. Hortic. Sci. 110:600-604. 